\title{
Tempo Integral
}

(Histórico e Evolução)

\section{Eduardo Pinto Pessoa Sobrinho}

O

instituto do Tempo Integral não é de criação recente, na nossa legislação de pessoal. Vem de longe a tentativa de dar uma gratificação especial, pela dedicação exclusiva do funcionário ao serviço público.

Os objetivos que se pretendem alcançar com essa modalidade de retribuição especial são os de institucionalizar o funcionário, fazendo-o dedicar-se única e exclusivamente ao serviço público, eliminando o empreguismo e diminuindo o número de servidores, através da eficiência, fazendo, assim, com que os funcionários existentes dêem maior rendimento, mediante o aumento das horas de trabalho.

Com êsse objetivo, a Lei $n^{2} 284$, de 28 de outubro de 1936 , que representou um grande passo na tentativa de melhorar a nossa organização administrativa e unificar a legislação de pessoal, autes dispersa, dispunha, no seu artigo 29:

«Art. 29. A juizo do Govêrno, e quando permitirem as condições financeiras do País, será estabelecido, para o exercício de certos cargos técnicos, científicos e de magistério, o regime de tempo integral.

$\S 1^{\circ}$, Para o funcionário de tempo integral serão fixados vencimentos superiores aos de seu cargo, os quais não poderão exceder de cem por cento dos vencimentos normais.

$\S 2^{\circ}$ As vantagens do tempo integral sòmente serão concedidas aos funcionários nomeados anteriormente a êste regime, caso se obriguem, expressamente, a não exercer qualquer outra função.

$\S 3$ ? Ficará sujeito à demissão, mediante inquérito administrativo, o funcionário que infringir o disposto nos parágrafos anteriores.» 
O Estatuto dos Funcionários de 1939 - Decreto-lei n 1.713 , de 28 de outubro de 1939 - também cuidou do Tempo Integral, estabelecendo no artigo 268:

«Art. 268. Poderá ser estabelecido o regime de tempo integral para os cargos e funções que a lei determinar.

Parágrafo único. O funcionário ocupante do cargo sujeito ao regime de tempo integral não poderá exercer qualquer outra atividade pública, ou particular, sob pena de demissão».

O atual Estatuto dos Funcionários - Lei $n^{\circ} 1.711$, de 28 de outubro de 1952 - dispõe mais sucintamente, no artigo 244 , que:

«Poderá ser estabelecido o regime de tempo integral para os cargos ou funções indicados em lei.»

A Lei $n^{\circ} 3.780$, de 12 de julho de 1960, que instituiu o sistema de Classificação de Cargos, dedicou um capitulo especial (o de $n^{\circ}$ XI) ao regime de Tempo Integral, estabelecendo o que se segue:

«Art. 49. O funcionário que exercer atividades técnico-cientificas, de magistério ou pesquisa, satisfeitas as exigências regulamentares, poderá optar pelo regıme de tempo integral.

$\S 1$. O regime de trabalho de que trata êste artigo é incompativel com o exercício cumulativo de cargos, empregos ou funções, bem como de qualquer outra atividade pública ou privada.

$\S 2$. Não se incluem na incompatibilidade prevista no parágrafo anterior as atividades que, sem caráter de emprêgo, se destinem a difusão e aplicação de idéias e conhecimentos; a prestação de assistência a outros serviços visando a aplicação de conhecimentos cientificos, quando solicitados através da direção da repartição a que pertence o servidor.

$\S 30$ O servidor que optar pelo regime de tempo integral assinará têrmo de compromisso, em que declare vincular-se ao regime e cumprir as condiçóes inerentes ao mesmo, fazendo jus aos benefícios do regime enquanto nêle permanecer, ressalvada a hipótese de aposentadoria.

Art. 50. O servidor em regime de tzmpo integral perceberá uma gratificação sob forma de acrésiimo proporcional ao nivel de vencimento do seu cargo, calculada de acôrdo com o tempo de efetivo exercício nesse regime, na forma da seguinte tabela:

Até 10 anos

Mais de 10 até 20 anos ............

Mais de 20 anos 
Art. 51. O servidor que, para optar pelo regime de tempo integral, fôr obrigado a desacumular, terá como gratificação importância não inferior à do vencimento do cargo desacumulado.

Art. 52. A gratificação de tempo integral, para efeito de cálculo de proventos, incorpora-se ao vencimento após 5 (cinco) anos de efetivo exercício nesse regime, encontrando-se o servidor, no ato da aposentadoria, a êle vinculado.»

Prosseguindo, determinou a Lei $n^{9} 4.345$, de 26 de junho de 1965, o que adiante se transcreve:

«Art. 11. Os funcionários do Serviço Civil do Poder Executivo, integrantes de órgãos da aciministração direta e das autarquias, que exerçam atividades de magistério, técnicas, de pesquisas ou científicas poderão ficar sujeitos ao regime de tempo integral e dedicação exclusiva, de acôrdo com a regulamentação a ser expedida, dentro do prazo de 60 (sessenta) dias, ficando revogados os dispesitivos constantes do Capítulo XI da Lei $\mathrm{n}^{\circ} 3.780$, de 12 de julho de 1960 .

$\S 1^{\circ}$ Pelo exercício do cargo em regime de tempo integral e dedicação exclusiva, será concedida, ao funcionário, gratificação fixada, no minimo, de $40 \%$ (quarenta por cento) do valor do vencimento do cargo efetivo, ficando revogadas as bases percentuais fixadas na Lei $\mathrm{n}^{\circ}$ 3.780, de 12 de julho de 1960 .

$\S 22^{\circ}$ A gratificação a que se refere o $\S 1^{\circ}$ dêste artigo será considerada, para efeito dos cálculos de proventos de aposentadoria, à razão de $1 / 30$ (um trinta avos) por ano de efetivo exercício em regime de tempo integral.

Art. 12. Considera-se regime de tempo integral o exercício da atividade funcional sob dedicação exclusiva, ficando o funcionário proibido de exercer cumulativamente outro cargo, função ou atividade particular de caráter empregatício profissional ou pública de qualquer natureza.

Parágrafo único. Não se compreendem na proibição dêste artigo:

I - o exercício em órgão de deliberação coletiva, desde que relacionado com o cargo exercido em tempo integral;

II - as atividades que, sem caráter de emprêgo, se destinam à difusão e aplicação de idéias e conhecimentos, excluidas as que impossibilitem ou prejudiquem a execução das tarefas inerentes ao regime de tempo integral; 
III - a prestação de assistência não remunerada a outros serviços, visando à aplicação de conhecimentos técnicos ou cientificos, quando solicitada através da repartição a que pertence o funcionário.»

A Lei $n^{9} 4.863$, de 29 de novembro de 1965, complementando o disposto nos arts. 11 e 12 da de $n^{\circ} 4.345$, de 1964, determinou:

"Art. 7\% O regime de tempo integral e dedicação exclusiva, a que se refere o art. 11 da Lei $n^{\circ} 4.345$, de 26 de junho de 1964, poderá ser aplicado, no interêsse da Administração e nos têrmos da regulamentação a ser expedida pelo Poder Executivo, em caráter obrigatório:

I - a cargos e funções que envolvam responsabilidade de Direção, Chefia ou Assessoramento;

II - a unidades administrativas, ou setores dos mesmos, quando a natureza do trabalho exigir;

III - às Equipes de Trabalho constituídas expressamente para operar sob o aludido regime;

IV - ao Magistério, em face de provadas necessidades de ensino e da cátedra, verificada, prèviamente, a viabilidade da medida em face das instalações disponíveis e outras condições de trabalho dos estabelecimentos de ensino;

V - a ocupantes de cargos compreendendo funções técnicas de nivel médio - auxiliares das atividades de magistério, técnicas e de pesquisa científica - quando participarem de trabalhos enquadrados nos itens anteriores.

$\S 1^{\circ}$ Em casos excepcionais, devidamente justificados, o regime de trabalho poderá ser aplicado a qualquer funcionário, individualmente, mediante proposta do dirigente da unidade administrativa.

$\S 2$. Excetuam-se da obrigatoriedade prevista neste artigo os funcionários que optarem pelo regime de tempo parcial de trabalho, salvo quando investidos em cargo ou função, de direção ou chefia, quando terão de invocar impedimento legal ou motivo justo.

$\S 3$ Excetuam $\sim \mathrm{se}$, igualmente, da obrigatoriedade prevista no $\S 2^{\circ}$, os ocupantes de cargos de direção $e$ chefia para os quais tenham sido nomeados em caráter efetivo.

$\S 4$ ㅇ O pessoal burocrático, auxiliar ou subalterno cujos serviços sejam indispensáveis ao funcionamento do regime a que se refere êste artigo, poderá ter o expediente prorrogado, percebendo gratificação pelo serviço extra- 
ordinário que prestar, independentemente de limite de tempo.

$\S 5$ : Caberá a uma Comissão designada pelo Presidente da República e subordinada ao Diretor-Geral do Departamento Administrativo do Serviço Público zelar pela fiel aplicação do regime de tempo integral e dedicação exclusiva, ressalvada a do pessoal pertencente ao magistério superior, regida pelas normas constantes do respectivo Estatuto.

$\S 6^{\circ}$ Ressalvado o que diga com o pessoal pertencente ao magistério superior, regido por normas próprias, constantes no respectivo Estatuto, e com o pesscal pertencente aos institutos de pesquisa científica ou tecnológica, cuja supervisão incumbirá ao Conselho Nacional de Pesquisas, a Comissão, com fundamento nos princípios legais e regulamentares, fixará critérios, expedirá instruções e exercerá supervisão, fiscalização e contrôle permanentes, podendo ouvir diretamente pessoas ou órgãos especializados e proceder, periòdicamente, a verificação in loco.

$\S 77^{\circ}$ Das decisões da Comissão caberá recurso para - Diretor-Geral do Departamento Administrativo do Serviço Público.

$\S 8^{\circ}$ A infringência dos compromissos decorrentes de regime de tempo integral e dedicação exclusiva, apurada em inquérito administrativo, será punida com a pena de demissão, a bem do serviço público.

$\S 9^{\circ}$ Os membros da Comissão farão jus a gratificação pela participação em órgão de deliberação coletiva, na forma da legislação em vigor.

$\S 10$. A gratificação de que trata o $\S 1^{\circ}$ do art. 11 da Lei $\mathrm{n}^{\circ} 4.345$, de 26 de junho de 1964, será fixada em decreto executivo, mediante proposta do Departamento Administrativo do Serviço Público, para os cargos a que se aplica o regime de tempo integral e dedicação exclusiva, tendo em vista a essencialidade, complexidade e responsabilidade das respectivas atribuições, bem como as condições do mercado de trabalho para as atividades correspondentes.

§11. A inclusão do servidor em regime de tempo integral será sempre da iniciativa do chefe do órgão onde o servidor estiver lotado.

$\S 12$. O regime de tempo integral será regulamentado em prazo não superior a 30 dias».

O Decreto-lei $n^{\circ} 81$, de 21 de dezembro de 1966, dispóe, ainda, o seguinte, sôbre Tempo Integral: 
«Art. 5 A gratificação pelo exercício em regime de tempo integral e dedicação exclusiva dos ocupantes de cargos ou funções de direção, chefia ou assessoramento, será calculada sôbre o valor do símbolo do cargo em comissão ou da função gratificada, observadas as normas da legislação em vigor e desde que o acréscimo da despesa não exceda de $25 \%$ (vinte e cinco por cento) da dotação orçamentária própria.

Art. $6^{\circ}$ É fixado em $50 \%$ (cinqüenta por cento) do vencimento do cargo efetivo o limite da gratificação pela prestação de serviço extraordinário, de que trata o \$ $4^{\circ}$ do art. $7^{\circ}$ da Lei nò 4.863 , de 29 de novembro de 1965 , ao pessoal burocrático, auxiliar ou subalterno, submetido a prorrogação ou antecipação de expediente, que se torne indispensável ao desempenho das atividades sob o regime de tempo integral e dedicação exclusiva.

Parágrafo único. O acréscimo de despesa decorrente do disposto neste artigo não excederá a dotação orçamentária própria de $20 \%$ (vinte por cento)».

O Decreto-lei n 200, de 25 de fevereiro de 1967, que dispóe sôbre a Reforma Administrativa, contém as seguintes normas sôbre
Tempo Integral:

"Art. 101. Ressalvados os cargos em comíssão definidos em ato do Poder Executivo como de livre escolha do Presidente da República, o pravimento em cargos em comissão e funções gratificadas obedecerá a critérios que considerem, entre outros requisitos, os seguintes:

III - Obrigar-se o funcionário, quando se caracterizar o interêsse da Administração, ao regime de tempo integral e dedicação exclusiva.

$\S 1^{\circ} \mathrm{Em}$ conseqüuência do disposto no inciso III dêste artigo, os funcionários que atenderem às condiçóes estipuladas ficam sujeitos ao regime de 40 (quarenta) horas semanais de trabalho e perceberão gratificação pelo regime de tempo integral e dedicação exclusiva.

Art. 108. O funcionário, em regime de tempo integral e de dedicação exclusiva, prestará serviços em dois turnos de trabalho, quando sujeito a expediente diário.

Parágrafo único. Incorrerá em falta grave, punível com demissão, o funcionário que perceber a vantagem de que trata êste artigo e não prestar serviços corres- 
pondentes e bem assim o chefe que atestar a prestação irregular dos serviços».

Apesar do longo período de tempo em que se fala no assunto e da multiplicidade da legislação dispondo sôbre Tempo Integral, tal regime só começou realmente a funcionar a partir de 1965 , com a criação da comissão prevista no $\S 5^{\circ}$ do art. $7^{\circ}$ da Lei $n^{\circ}$ 4.863-65, que se denominou de «Comissão de Tempo Integral e Dedicação Exclusiva - COTIDE».

O regime de Tempo Integral foi regulamentado pelos Decretos $\mathrm{n}^{2 \mathrm{~s}}$ 54.061, de 28-7-64, 57.744, de 3 de fevereiro de 1966 e 60.091 , de 18 de janeiro de 1967, êste último ora vigente.

Da longa exposição feita através da transcrição da legislação que, desde 1936, se dedicou ao assunto, chega-se à conclusão de que o regime de Tempo Integral e Dedicação Exclusiva, atualmente em vigor, poderá ser aplicado, em benefício do serviço, aos ocupantes de cargos e funções.

a) de magistério, à vista de provadas necessidades de ensino e da cadeira, verificada, prèviamente, a viabilidade da medida, em face das instalações disponiveis e outras condições de trabalho do estabelecimento;

b) com atribuições técnicas, científicas ou de pesquisas;

c) que envolvam a responsabilidade de direção, chefia e assessoramento;

d) que compreendam funções técnicas de nivel médio auxiliares de ątividades de magistério, técnicas ou de pesquisas cientificas.

A adoção do regime de Tempo Integral e Dedicação Exclusiva será, sempre, de iniciativa do chefe de repartição diretamente subordinado ao Ministro de Estado, a dirigente de autarquia ou órgão subordinado ao Presidente da República, não sendo levados em consideração os pedidos individuais ou as reclamações pela omissão de um funcionário no grupo encarregado do respectivo programa de trabalho.

As propostas deverão ser fundamentadas e devidamente justificadas, constando das mesmas:

I - Subprograma de trabalho a ser executado no regime de Tempo Integral, com os objetivos a serem alcançados;

II - relação numérica dos cargos necessários à sua execução.

De acôrdo com as reais necessidades do serviço o regime poderá ser aplicado ao conjunto de funcionários de determinadas unidades administrativas ou a setores de trabalho das mesmas, bem como a equipes de trabalho constituídas para operar sob êsse regime.

Em casos excepcionais, devidamente justificados, o regime de tempo integral e dedicação exclusiva poderá ser aplicado, individualmente, a qualquer funcionário. 
O regime de Tempo Integral e Dedicação Exclusiva, regulamentado pelo Decreto $n^{\circ}$ 60.091, de 1967, não se aplica aos seguintes servidores:

a) aos membros do corpo docente do magistério superior;

b) aos funcionários pagos sob o regime de remuneração;

c) aos Ministros de Estado, Chefes do Gabinete Civil e do Gabinete Militar da Presidência da República e do Serviço Nacional de Informações;

d) ao Prefeito do Distrito Federal;

e) ao Secretário da Prefeitura do Distrito Federal;

f) aos Magistrados;

g) aos Membros do Tribunal de Contas da União;

h) aos membros do Ministério Público Federal e do Serviço Jurídico da União;

i) aos Funcionários Policiais Civis

Cabe aos Ministros de Estado ou dirigentes de órgãos diretamente subordinados à Presidência da República encaminhar ao Departamento Administrativo do Pessoal Civil, em duas vias, as propostas apresentadas pelos órgãos subordinados, acompanhadas da respectiva programação geral.

Quando se tratar de entidade autárquica, a proposta deverá ser encaminhada pelo Ministro do Estado ao qual esteja a mesma vinculada.

À COTIDE cabe zelar pela fiel aplicação do regime de Tempo Integral e Dedicação Exclusiva, competindo-lhe expedir instruções e exercer supervisão, fiscalização e contrôle permanente, para a fiel execução do regime.

As penalidades previstas para o caso de infração das normas do Tempo Integral são severas, não sòmente para os funcionários faltosos, como também para os chefes de repartição ou serviço que não fiscalizem convenientemente a real prestação dos serviços,

Para a subsistência do regime é necessário, entretanto, que todos - dirigentes e dirigidos - compreendam que o mesmo não representa simples aumento de vencimentos, mas exige maior soma de trabalho e real dedicação ao serviço. Assim é necessário que os subprogramas que justificam a implantação do sistema sejam convenientemente organizados, com objetivos claros e definidos, não se limitando à simples enumeração dos encargos normais, rotineiros e regimentais do órgão, mas constituam um plano de trabalho, com objetivos claramente expostos, demonstrando, precisamente, os resultados que se espera sejam alcançados, para facilitar a fiscalização de sua execução e contrôle dos objetivos colimados, e que os mesmos sejam efetivamente cumpridos.

O regime de Tempo Integral e Dedicação Exclusiva cessará:

a) automàticamente, na conclusão da tarefa, no caso em que houver sido instituída para a realização de certo e determinado trabalho; 
b) por determinação do Ministro de Estado, do dirigente da autarquia ou de órgão diretamente subordinado ao Presidente da República, quando, a juízo dessas autoridades, deixar cie corresponder às finalidades para que foi instituído;

c) a pedido do funcionário, por justa causa.

O funcionário em regime de Tempo Integral e Dedicação Exclusiva percebe uma gratificação básica de $40 \%$ (quarenta por cento), que poderá ser acrescida das seguintes parcelas, em função das respectivas atribuições:

a) até $20 \%$ (vinte por cento), pela essencialidade; sabilidade;

b) até $20 \%$ (vinte por cento), pela complexidade e respon-

c) até $20 \%$ (vinte por cento), pela dificuldade de recrutamento, em face das condições do mercado de trabalho.

No caso de cargos ou função de direção, chefia, assessoramento ou secretariado, a gratificação será calculada sôbre o valor do símbolo do cargo em comissão ou da função gratificada. A êsse respeito vale salientar que, na conformidade da legislação vigente, ao funcionário nomeado ou designado para o exercício de encargos de direção ou chefia e assessoramento é facultado optar pela percepção do vencimento e demais vantagens do seu cargo efetivo, acrescido de gratificação fixa, correspondente a $20 \%$ do valor do cargo em comissão ou do símbolo da função gratificada respectiva $\left(\S 2^{\circ}\right.$ do art. $1^{\circ}$ e $\S 3^{\circ}$ do art. $2^{\circ}$ da Lei $n^{\circ} 4.345$, de 1964).

É de justiça que, no caso de Tempo Integral, seja aplicado o mesmo critério, devendo ser facultado ao funcionário no exercício de cargo em comissão ou de função gratificada, optar pela gratificação calculada sôbre o vencimento do seu cargo efetivo.

Os percentuais de essencialidade obedecem ao seguinte critério:

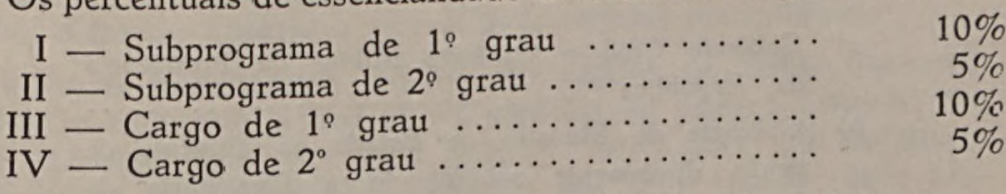

A classificação, em razão da essencialidade, dos subprogramas resulta da sua maior ou menor prioridade, dentro da programação geral do Ministério, autarquia ou órgão diretamente subordinado ao Presidente da República, observados os objetivos e finalidade de cada um. O que pode ser essencial em um Ministério, por exemplo, pode ser secundário em outro.

Em relação a cada cargo deverá ser indicado, também, o grau de essencialidade dentro do respectivo subprograma de trabalho.

Os percentuais de complexidade e responsabilidade são atribuidos de acôrdo com o seguinte critério: 


\section{I - Cargos em comissão:}

Símbolos 1 a $4 \ldots \ldots \ldots \ldots \ldots \ldots \ldots \ldots$

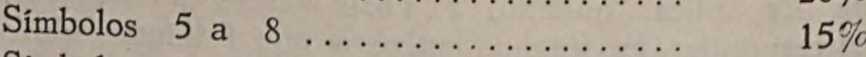

Simbolos 9 a $12 \ldots \ldots \ldots \ldots \ldots \ldots \ldots .10 \%$

II - Funções gratificadas:

Simbolos 1 a $6 \ldots \ldots \ldots \ldots \ldots \ldots \ldots \ldots$

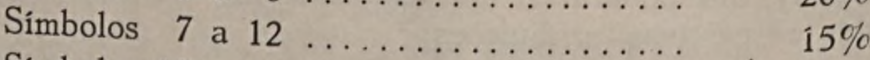

Simbolos 13 a $20 \ldots \ldots \ldots \ldots \ldots \ldots \ldots \ldots . .10 \%$

III - Cargos efetivos:

Niveis 19 a 22 e vencimentos superiores $\quad 20 \%$

Niveis 12 a $18 \ldots \ldots \ldots \ldots \ldots \ldots \ldots \ldots$

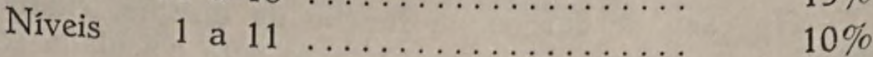

Os percentuais de mercado de trabaiho são atribuídos pela COTIDE, de acôrdo com o seguinte critério:

\footnotetext{
I - Mercado escasso $\ldots \ldots \ldots \ldots \ldots \ldots \ldots \ldots . \ldots \ldots$

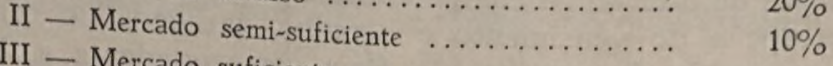

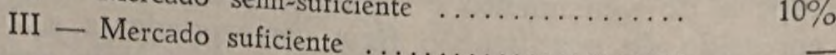

Exclusiva funcionário em regime de Tempo Integral e Dedicação da gratificaç̃̃á perceber, ainda, juntamente com os montantes dade, complexidade e dos percentuais referentes à essencialimento, antes expo e responsabilidade e dificuldade de recrutaGabinete, de expostos, percentual suplementar pelo exercício em

I - Hierarquia do órgão:
a) Gabinete Civil e Gabinete Militar da Presidência da República ........................................
b) Gabinete de Ministro de Estado ou dirigente de $15 \%$ órgão diretamente subordinado à Presidência da República
c) Gabinete de dirigente de autarquia $\ldots \ldots \ldots \ldots \ldots . . .6 \%$

II - Encargos e hierarquia da função:

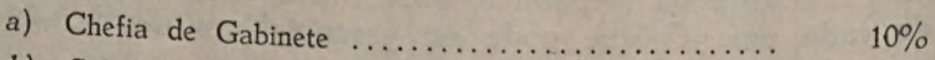

b) Subchefia de Gabinete ..................... $7 \%$

c) Assessor, Oficial de Gabinete e assemelhados .... $4 \%$

O funcionário em regime de tempo integral e dedicação exclusiva deve empregar no serviço público não sòmente o seu 
tempo de serviço, mas, ainda, tôdas as suas atividades. Não pode, assim, exercer, cumulativamente, outro cargo, emprêgo ou incumbir-se de atividades particulares de caráter empregatício, profissional.

As únicas exceções admitidas são:

a) o exercício em órgão de deliberação coletiva, desde que diretamente relacionado com o cargo em regime de tempo integral;

b) as atividades que, sem caráter de emprêgo, se destinam à difusão de conhecimentos, excluídas as que prejudiquem a execução das obrigações inerentes ao regime de tempo integral e dedicação exclusiva;

c) a prestação eventual de assistência não remunerada a outros órgãos do serviço público, visando à aplicação de conhecimentos técnicos ou científicos, quando solicitada através da repartição a que pertencer o funcionário;

d) a participação eventual, sem caráter empregatício, em atividades didáticas de seminários, conferências e outras semelhantes, bem como a ministração de ensino especializado, em cursos temporários de estabelecimento oficial de nivel superior.

Sem prejuízo de ficar à disposição do órgão em que estiver servindo, sempre que as necessidades do serviço o exigirem, o funcionário sujeito ao regime de tempo integral fica obrigado ao minimo de quarenta horas semanais de trabalho, salvo quando se tratar de atividade de magistério, caso em que o periodo de trabalho previsto na legislação específica será acrescido de, no minimo, seis horas semanais.

Os servidores em regime especial de serviço extraordinário ficam obrigados à prestação, no minimo, de 10 horas semanais de trabalho, além do horário a que estiver sujeito normalmente.

Tanto os funcionários sujeitos ao regime de tempo integral e dedicação exclusiva, como os submetidos ao regime especial de serviço extraordinário, por uma questão de higiene do trabalho, são obrigados a prestar seus serviços em dois turnos, com um intervalo de pelo menos uma hora, para refeição e descanso.

A gratificação de tempo integral e dedicação exclusiva está incluida no teto do vencimento de que trata o art. 35 do Decretolei $n^{\circ} 81$, de 21 de dezembro de 1966, modificado pelo Decreto-lei no 177 , de 16 de fevereiro de 1967 .

O funcionário em gôzo da gratificação de tempo integral e dedicação exclusiva não sofrerá descontos nos afastamentos resultantes de férias, casamento, luto, júri, serviço eleitoral, por prazo não superior a 30 dias, no periodo imediatamente anterior e subseqüente às eleições, e licença para tratamento de saúde. 
O pessoal burocrático, auxiliar ou subalterno, cujo trabalho seja considerado indispensável ao funcionamento do regime de Tempo Integral e Dedicação Exclusiva, poderá ser submetido a serviço extraordinário, em regime especial, pelo prazo de que se fizer necessário, percebendo gratificação mensal fixada em 50\% do nível de vencimento, a qual poderá ser acrescida de $25 \%$, quando se tratar de serviço noturno.

Êste trabalho não tem maior pretensão, nem caráter doutrinário. Visou, apenas, dar uma idéia da evolução e dos princípios que regulam a matéria em nossa legislação de pessoal. 